BORELLA, G. et al. Alimentação e grupo genético de ovinos terminados em confinamento:

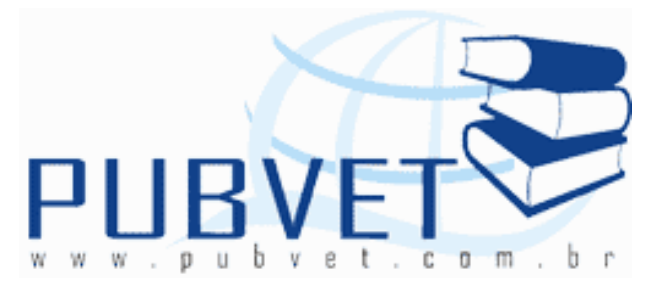

PUBVET, Publicações em Medicina Veterinária e Zootecnia.

\title{
Alimentação e grupo genético de ovinos terminados em confinamento - Revisão de literatura
}

Graciela Borella2 , Alexandre Agostinho Mexia ${ }^{1}$, Suelen Corrêa da Silva², Jocilaine Garcia1, Luiz Juliano Valério Geron ${ }^{1}$.

${ }^{1}$ Professor do Departamento de Zootecnia. Universidade do Estado de Mato Grosso (UNEMAT).

2 Alunas de graduação do Curso de Zootecnia da Universidade do Estado de Mato Grosso. Autor para correspondência: suelencorrea z@hotmail.com

\section{Resumo}

O presente trabalho teve como objetivo revisar os fatores que estão relacionados à produção de ovinos em sistema de confinamento, em que o cordeiro é a categorial animal que fornece carne de melhor qualidade, sendo que o peso da carcaça e suas características são influenciadas pelo peso de abate, raça, sexo, idade entre outros fatores. O consumo de alimento vai depender da aceitabilidade do animal, das condições do ambiente sobre o animal, temperaturas e a disponibilidade do alimento, buscando sempre atender as exigências dos mesmos. Deve ser verificado o peso de abate para que se obtenham carcaças de qualidade e que o excesso de gordura não afete o produto final. A escolha da raça ou grupo genético é importante para o confinamento, pois os animais devem mostrar seu potencial para produção de carne.

Palavras-chave: carne, cordeiro, mercado consumidor, terminação 
BORELLA, G. et al. Alimentação e grupo genético de ovinos terminados em confinamento: Revisão de literatura. PUBVET, Londrina, V. 5, N. 1, Ed. 148, Art. 995, 2011.

\title{
Feeding and genetic group of sheep in feedlot termination
}

\begin{abstract}
The present work had as its aim to review the factors that are related to sheep production in feedlot system, which the Lamb is the animal category that provides the meat of better quality, the carcass weight and its characteristics are influenced by the slaughter weight, race, sex, age among other factors. The food consumption will depend on the animal aceptability, on the environmental condition under the animals, temperatures and food availability, aiming to attend the animals demand. It must be verified the slaughter weight to obtain carcasses with quality and in that the excess of fat does not affect the the final product. The race choice and genetic group is important to termination, because the animals must show their potential to meat production.
\end{abstract}

Keywords: meat, lamb, consumer market, finishing.

\section{INTRODUÇÃO}

O Brasil possui aproximadamente 17 milhões de cabeças de ovinos, dos quais $45 \%$ encontram-se na região Nordeste. Entretanto, outras regiões como Sudeste e o Centro-Oeste, têm apresentado elevado crescimento da atividade, sendo que no Estado de Mato Grosso, o crescimento do rebanho foi de $37 \%$ ao ano nos últimos anos (SANTOS et al., 2008).

Recentemente, esta atividade no Brasil vem aumentando significativamente, estimulada pelo elevado potencial de consumo dos grandes centros urbanos nacionais. A crescente demanda impulsiona o aumento da produção da carne de cordeiros para o abate, gerando a necessidade de melhorias nas técnicas de produção.

Uma das peculiaridades da espécie é apresentar alta eficiência para ganho de peso e qualidade da carcaça, nos primeiros seis meses de vida, somando-se ainda o rápido ciclo reprodutivo, pois com 9 meses, incluindo 5 de gestação, já 
BORELLA, G. et al. Alimentação e grupo genético de ovinos terminados em confinamento: Revisão de literatura. PUBVET, Londrina, V. 5, N. 1, Ed. 148, Art. 995, 2011.

é possível o abate dos animais.

A produção de carne ovina apresenta-se como uma atividade alternativa, capaz de adicionar renda aos negócios, não só dos ovinocultores em si, mas à atividade rural como um todo, independente de se ter ou não tradição na criação de ovinos.

O cordeiro é a categoria animal que fornece carne de melhor qualidade e apresenta, nessa fase, os maiores rendimentos de carcaça e maior eficiência de produção, devido a sua alta velocidade de crescimento. Dentre outras alternativas eficazes para terminação dos mesmos, o confinamento tem despertado o interesse dos ovinocultores (PIRES et al., 2000).

De acordo com Macedo (1998), o confinamento de ovinos pode ser uma alternativa bastante viável na busca de fontes alternativas de proteína de alto valor biológico, custo relativamente baixo e produção rápida, o que possibilita contribuir de forma efetiva a crescente demanda da humanidade.

O sistema de confinamento consiste na terminação de animais instalados em piquetes ou currais com área restrita, em que os alimentos e a água necessários são fornecidos em cochos, sendo, segundo Oliveira et al. (2003), uma alternativa para intensificar a produção de carne, devido à maior rapidez com que os animais chegam ao ponto de abate e pela maior facilidade de controlar as verminoses. No entanto, este tipo de criação requer maior investimento no que se refere às instalações, alimentação e mão-de-obra.

De acordo com Santos (2004) é muito importante que os cordeiros destinados à terminação confinada tenham sido bem manejados na fase de amamentação, sobretudo no que diz respeito à verminose. As seqüelas deixadas pelos helmintos são irreversíveis, com prejuízos definitivos ao bom desempenho dos animais.

Em qualquer sistema de produção animal, procura-se sempre adequar e equacionar suprimento e demanda por alimento. Todos os esforços e recursos são despendidos no sentido de que a quantidade de alimento disponível seja suficiente para atender as exigências, tanto quantitativas, quanto qualitativas do rebanho (SILVA e PEDREIRA, 1997). 
BORELLA, G. et al. Alimentação e grupo genético de ovinos terminados em confinamento: Revisão de literatura. PUBVET, Londrina, V. 5, N. 1, Ed. 148, Art. 995, 2011.

Em relação a elaboração das rações, é importante ter conhecimento de três componentes básicos que são: a composição química e energética dos alimentos a serem utilizados, os custos e as exigências nutricionais dos animais. Sendo que, as exigências nutricionais dos animais quando mal ajustadas às características da espécie, categoria animal, sexo, estado fisiológico e nível de produção, comprometem o desempenho animal, resultando em perdas econômicas (ESTRADA, 2008).

Além do sistema de criação adotado e os manejos empregados para maximização da atividade, outros fatores comerciais também devem ser levados em consideração. Dentre esses, peso ideal ao abate é aquele em que a proporção de músculos na carcaça é máxima e a gordura, suficiente para conceder à carne, propriedades sensoriais adequadas à preferência do mercado consumidor. Por outro lado, há que se considerar também a eficiência de conversão alimentar do cordeiro, que diminui, à medida que o peso corporal aumenta (SIQUEIRA et al., 2001).

Portanto, a ovinocultura busca apresentar ao mercado consumidor produtos de excelente qualidade de carcaça, com animais terminados em um curto período, atendendo assim as exigências atuais.

Objetivou-se nesta revisão avaliar fatores que estão relacionados à produção de ovinos em confinamento.

\section{REVISÃO BIBLIOGRÁFICA}

\subsection{Prática do Confinamento}

A criação de cordeiros é uma atividade muito promissora do agronegócio atualmente. O mercado da ovinocultura cresce com uma taxa cada vez mais acentuada e com retorno muito rápido. Por se tratar de animal jovem, o cordeiro apresenta alta eficiência de ganho de peso, os gastos com alimentação concentrada são baixos e a precocidade ao abate compensados pelo giro rápido. Com essa eficiência de produção, a ovinocultura pode se 
BORELLA, G. et al. Alimentação e grupo genético de ovinos terminados em confinamento: Revisão de literatura. PUBVET, Londrina, V. 5, N. 1, Ed. 148, Art. 995, 2011.

tornar cada vez mais rentável frente a outros setores da pecuária (CALFAT, 2009).

Clementino et al. (2007) afirmaram que para se ter um espaço maior no mercado da carne ovina, é preciso melhorar o sistema de produção. A maioria dos criadores coloca à venda animais com idade avançada e com características de carcaças indesejáveis e de baixo rendimento corporal.

Com o crescimento da ovinocultura, é necessário que os produtores tenham uma postura empresarial e realizem as avaliações de custos e rentabilidade (BARROS et al, 2009).

Silva e Pires (2000) argumentaram que no sistema de produção de carne, as características qualitativas e quantitativas de carcaça são de fundamental importância, devido ao fato de estas características estarem diretamente relacionadas ao produto final da carne. Sendo que o peso da carcaça e suas características são influenciadas pelo peso de abate, raça, sexo, idade entre outros fatores.

A duração do período dos animais em confinamento deve variar entre 56 e 70 dias, sendo que os cinco a sete primeiros dias deste período deve ser visto como de adaptação dos animais, em especial, aos alimentos. No entanto, quando o acabamento for feito a pasto, a duração máxima do período pode chegar a 90 dias (SIMPLICIO et al., 2002).

De acordo com Santos (2004), como o confinamento é um período de engorda intensiva de animais, algumas vantagens podem ser levadas em consideração nesta prática, a redução da idade de abate, racionalização da mão-de-obra da propriedade, aproveitamento de alimentos da própria fazenda, permite a comercialização dos animais com peso e carcaças uniformes, produzir carcaças terminadas com camada de gordura uniforme ideal para evitar ressecamento durante o processo de refrigeração, entre outros fatores.

\subsection{Ingestão de Matéria Seca}

De acordo com Berchielli et al. (2006), a ingestão de alimento é de 
BORELLA, G. et al. Alimentação e grupo genético de ovinos terminados em confinamento: Revisão de literatura. PUBVET, Londrina, V. 5, N. 1, Ed. 148, Art. 995, 2011.

importância fundamental na alimentação animal, porque dela vai depender a quantidade total de nutrientes que o animal recebe para crescimento, saúde e produção.

Quando os animais não recebem uma alimentação adequada em quantidade certa e de boa qualidade em todas as épocas do ano, eles não são capazes de expressar seu potencial produtivo, reduzindo assim a importância do melhoramento zootécnico e controle sanitário do rebanho (MEDEIROS et al., 1994).

Segundo Ribeiro (1997), existem dois mecanismos básicos para o controle de ingestão do alimento. Primeiro, o animal atende sua necessidade energética e o estímulo para a ingestão do alimento cessa. Isso ocorre em animais com pouca exigência e/ou que estão recebendo uma ração bem balanceada. Segundo, as necessidades do animal ainda não foram atendidas, mas o rúmen se torna repleto, sem capacidade física para a ingestão de mais alimento. Isso ocorre em animais com altas exigências e/ou que recebem alimentação de baixa qualidade.

Borges (1999) relatou que nos ruminantes o controle da ingestão do alimento é peculiar, devido a existências dos pré-estômagos. Dietas de baixo valor nutritivo, ou seja, baixa digestibilidade, o consumo de alimento aumenta com o valor nutritivo, até um ponto em que a distensão ruminal permita maior ingestão. Com o aumento do valor nutritivo, há um aumento no consumo até que o ponto estabelecido pela demanda nutricional e fisiológica seja alcançado.

Um modelo teórico (Figura 1) de como é a relação entre a concentração de um nutriente essencial ao animal e seu consumo voluntário é dado por Forbes (1995). Através deste modelo, ilustra-se de forma didática que o consumo voluntário normal é atingido quando os nutrientes essenciais estão em concentração suficientes para atender às exigências do animal.

Com teores pouco superiores às exigências, o consumo não é afetado, mas quando os teores são excessivos, chegando a níveis tóxicos, ou deficientes em demasia provocam uma drástica redução no consumo. Outro fato ilustrado na Figura 1 e que normalmente pode ser observado, é o 
BORELLA, G. et al. Alimentação e grupo genético de ovinos terminados em confinamento: Revisão de literatura. PUBVET, Londrina, V. 5, N. 1, Ed. 148, Art. 995, 2011.

consumo exacerbado com níveis de deficiência marginal. Isto ocorre, pois o animal, numa tentativa de atender suas exigências, consome mais que o normal até um limite físico.

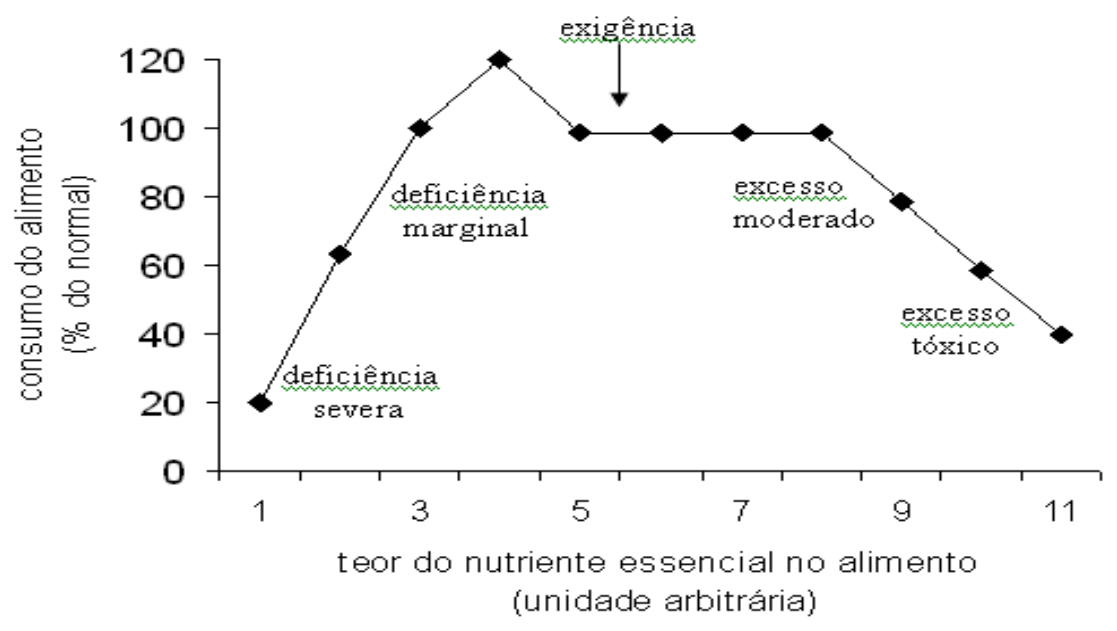

Figura 1. Modelo didático da influência da composição química do alimento no consumo voluntário (adaptado de Forbes, 1995)

Bendahan e Braga (2005) afirmaram que cordeiros em confinamento apresentam altas exigências nutricionais, com $18 \%$ de proteína bruta, 70 a $78 \%$ NDT (nutrientes digestíveis totais), 0,45 \% de cálcio ( $\mathrm{Ca}$ ) e 0,25\% de fósforo $(P)$ na matéria seca total. Consumindo cerca de 4,5 a $5 \%$ do peso vivo em matéria seca, com um fornecimento de $60 \%$ de ração concentrada, a base de milhos e farelados de oleaginosas e $40 \%$ de volumoso de boa qualidade.

O consumo de determinado alimento vai depender principalmente do grau de aceitabilidade do animal (Medeiros et al., 1994). Sendo assim, Valverde (2005) enfatiza que a capacidade do consumo é ligada também a velocidade da passagem pelo tubo digestório, efeito do ambiente sobre o animal, como temperaturas altas ou baixas, que irão deprimir o consumo e a quantidade de alimento à disposição do animal.

Pequenos ruminantes apresentam hábitos alimentares característicos, com preferência bem definidas. No entanto, uma mesma ração pode ser consumida em quantidades diferentes, dependendo da maneira e da freqüência com que é 
BORELLA, G. et al. Alimentação e grupo genético de ovinos terminados em confinamento: Revisão de literatura. PUBVET, Londrina, V. 5, N. 1, Ed. 148, Art. 995, 2011.

oferecida (RIBEIRO, 1997).

O comportamento alimentar também pode ser influenciado por vários fatores externos, como condições do ambiente e constituintes da dieta. Em ruminantes, o consumo de alimento é regulado por mecanismos que atuam a longo e curto prazo. No entanto, o local primário responsável pelo controle integrado da ingestão de alimento e equilíbrio energético no corpo é o sistema nervoso central. Peptídeos encontrados no sistema nervoso central parecem ter um efeito direto no controle do metabolismo, ingestão de alimento. Existem vários sistemas receptores neste sistema e, também no sistema nervoso periférico que fornecem informações sobre o estado metabólico do animal, coordenando o comportamento alimentar, assim, o consumo é regulado por mecanismos físicos, químicos, metabólicos, neuro-hormonais e também pela ingestão de água (BERCHIELLI et al., 2006).

De acordo Borges e Bresslau (2003) os principais fatores que controlam ou que interferem no consumo de matéria seca que estão ligados ao alimento, é o teor de proteína da dieta, percentual de umidade da dieta, estrutura física do alimento e a quantidade de concentrado na dieta. Os fatores ligados ao manejo são a disponibilidade do alimento, manejo dos cochos, freqüência das refeições, disponibilidade de água, variações na dieta e sequência alimentar. E os fatores ligados ao ambiente como interações sociais, temperatura e umidade e a presença de insetos nocivos, que também interferem no consumo.

É de grande importância o consumo de alimento pelo animal, pois este é fundamental para o organismo e determina o nível de nutrientes ingeridos, obtendo assim a produção como resposta (Van Soest, 1994), normalmente estes são expressos em relação ao peso vivo. Este valor varia conforme o tamanho e nível de produção do animal, existindo variações de consumo ao longo do ciclo de produção e em função da digestibilidade dos alimentos (BORGES e BRESLAU, 2003).

Numerosos fatores relacionados tanto com o animal, quanto com o alimento, assim como, diferenças de hábito alimentar ocasionadas pela 
BORELLA, G. et al. Alimentação e grupo genético de ovinos terminados em confinamento: Revisão de literatura. PUBVET, Londrina, V. 5, N. 1, Ed. 148, Art. 995, 2011.

pressão da seleção e evolução das espécies, têm grande influencia no consumo de matéria seca (CMS). As formas de expressar o CMS são: quilogramas de matéria seca por animal/dia ( $\mathrm{kg} \mathrm{MS/animal/dia)} \mathrm{sendo} \mathrm{a} \mathrm{forma} \mathrm{mais} \mathrm{comum}$ para expressar o CMS; em função de $100 \mathrm{~kg}$ de peso corporal (kg de MS/100 kg PC ou \%PC), e por Unidade de Tamanho Metabólico (UTM), ou seja, g de MS por unidade de (Peso Corporal) ${ }^{0,75}$ (ESTRADA, 2000).

Normalmente, para estas formulações usa-se o "Nutrient Requirements of Sheep" (National Research Council - NRC, 1985) e "Energy and Protein Requirements of Ruminants" (Agricultural and Food Research Council - AFRC, 1993). Contudo em nosso país ainda não existem dados suficientes que permitam a elaboração de tabela de exigências nutricionais brasileiras para ovinos. Portanto não se pode descartar as já produzidas em outras partes do mundo, pois, quando bem analisadas, podem servir de parâmetros para nosso país (Tabela 1 ).

Tabela 1: Ganho de peso e consumo de matéria seca diário de cordeiros

\begin{tabular}{ccc}
\hline Peso $(\mathrm{kg})$ & $\mathrm{GP}(\mathrm{g} / \mathrm{d})$ & $\mathrm{CMS}(\mathrm{kg})$ \\
\hline Cordeiros recém desmamados & potencial de crescimento & moderado \\
10 & 200 & 0,5 \\
20 & 250 & 1,0 \\
30 & 300 & 1,3 \\
Cordeiros recém desmamados & potencial de crescimento rápido \\
10 & 250 & 0,6 \\
20 & 300 & 1,2 \\
30 & 325 & 1,4 \\
$4-7$ meses de idade & & 1,3 \\
30 & 295 & 1,6 \\
40 & 275 &
\end{tabular}

$\mathrm{GP}=$ Ganho de peso; $\mathrm{CMS}=$ Consumo de matéria seca.

Fonte: NRC, 1985

Turino et al. (2007) ao trabalharem com 60 cordeiros da raça Santa Inês para avaliar a substituição da fibra em detergente neutro (FDN) do bagaço de cana-de-açúcar in natura (BIN) pela FDN da casca de soja (CS), concluíram que animais alimentados com dietas contendo CS obtiveram maior 
BORELLA, G. et al. Alimentação e grupo genético de ovinos terminados em confinamento: Revisão de literatura. PUBVET, Londrina, V. 5, N. 1, Ed. 148, Art. 995, 2011.

GMD. A CS promove melhor desempenho quando comparada ao BIN e pode ser utilizada como fonte de fibra para cordeiros terminados com dietas contendo alta proporção de concentrado. Valores encontrados na Tabela 2.

Tabela 2: Peso vivo inicial e final, consumo de matéria seca (CMS), ganho médio diário de peso (GMD) e conversão alimentar (CA) dos cordeiros

\begin{tabular}{|c|c|c|c|c|c|}
\hline \multicolumn{6}{|c|}{ Tratamento $^{(1)}$} \\
\hline Item & $100 \mathrm{C}$ & BIN $14^{(2)}$ & BIN $18^{(3)}$ & CS $14^{(2)}$ & $\operatorname{CS} 18^{(3)}$ \\
\hline PI $(\mathrm{kg})$ & 16,63 & 16,51 & 16,35 & 16,22 & 16,37 \\
\hline $\mathrm{PF}(\mathrm{kg})$ & 35,18 & 36,44 & 33,36 & 36,94 & 38,07 \\
\hline CMS (kg/dia) & 0,78 & 0,87 & 0,78 & 0,86 & 0,93 \\
\hline GMD (g/dia) & 220,67 & 237,33 & 202,17 & 246,67 & 258,17 \\
\hline $\mathrm{CA}(\mathrm{kg} \mathrm{MS} / \mathrm{kg}$ ganho) & 3,89 & 3,68 & 3,93 & 3,50 & 3,59 \\
\hline
\end{tabular}

(1) Tratamentos: 100C: 100\% de concentrado; BIN14: $95 \%$ de concentrado e 5\% de BIN; BIN18: $90 \%$ de concentrado e $10 \%$ de BIN; CS14: $92 \%$ de concentrado e $8 \%$ de CS e CS18: $88 \%$ de concentrado e $12 \%$ de CS; ${ }^{(2)} 14 \%$ de FDN na dieta; ${ }^{(3)} 18 \%$ de FDN na dieta. Adaptado de Turino et al. (2007)

$\mathrm{Na}$ Tabela 03 estão demonstrados alguns trabalhos com ovinos relacionando o consumo com diferentes fontes de alimentos e em diferentes níveis, avaliando o consumo de MS ( $\mathrm{kg})$, consumo de MS (\% PC) e a CA. 
BORELLA, G. et al. Alimentação e grupo genético de ovinos terminados em confinamento: Revisão de literatura. PUBVET, Londrina, V. 5, N. 1, Ed. 148, Art. 995, 2011.

Tabela 3: Dados experimentais de trabalhos com ovinos

\begin{tabular}{|c|c|c|c|c|c|}
\hline Trabalho & Alimentação & $\begin{array}{l}\text { Consumo } \\
\text { MS (kg) }\end{array}$ & $\begin{array}{l}\text { Consumo } \\
\text { MS (\%PC) }\end{array}$ & CA & Referência \\
\hline $\begin{array}{l}\text { Fonte de óleo vegetal na dieta de } \\
\text { cordeiros em confinamento }\end{array}$ & $\begin{array}{l}\text { Dieta controle } \\
\text { Com óleo de soja } \\
\text { Com óleo de canola } \\
\text { Com óleo de linhaça }\end{array}$ & $\begin{array}{l}1,040 \\
0,980 \\
0,980 \\
0,970\end{array}$ & $\begin{array}{l}4,55 \\
4,20 \\
4,05 \\
4,24\end{array}$ & $\begin{array}{l}3,5 \\
3,57 \\
3,89 \\
3,95\end{array}$ & $\begin{array}{l}\text { Yamamoto } \\
\text { et al. (2005) }\end{array}$ \\
\hline $\begin{array}{l}\text { Desempenho e digestibilidade aparente } \\
\text { em ovinos confinados alimentados com } \\
\text { dietas contendo níveis crescentes de } \\
\text { caroço de algodão integral }\end{array}$ & $\begin{array}{l}0 \% \text { caroço de algodão } \\
20 \% \text { caroço de algodão } \\
30 \% \text { caroço de algodão } \\
40 \% \text { caroço de algodão }\end{array}$ & $\begin{array}{l}1,226 \\
1,236 \\
1,126 \\
1,192\end{array}$ & $\begin{array}{l}4,66 \\
4,74 \\
4,47 \\
4,58\end{array}$ & $\begin{array}{l}6,01 \\
6,71 \\
7,62 \\
6,90\end{array}$ & $\begin{array}{l}\text { Cunha et al. } \\
\qquad(2008)\end{array}$ \\
\hline $\begin{array}{l}\text { Consumo de nutrientes e desempenho } \\
\text { de ovinos alimentados com dieta à base } \\
\text { de cana-de-açúcar hidrolizada }\end{array}$ & $\begin{array}{l}\text { In natura } \\
\text { Hidrolizada } 0,5 \% \text { cal } \\
\text { Hidrolizada } 0,9 \% \text { cal }\end{array}$ & $\begin{array}{l}0,966 \\
0,936 \\
0,963\end{array}$ & $\begin{array}{l}3,97 \\
3,96 \\
3,93\end{array}$ & $\begin{array}{l}8,2 \\
8,7 \\
7,0\end{array}$ & $\begin{array}{l}\text { Freitas et al. } \\
\quad(2008)\end{array}$ \\
\hline $\begin{array}{l}\text { Consumo de nutrientes e desempenho } \\
\text { de cordeiros em confinamento } \\
\text { alimentados com dietas com polpa } \\
\text { cítrica úmida prensada em substituição } \\
\text { a silagem de milho }\end{array}$ & $\begin{array}{l}0 \% \text { de polpa cítrica } \\
25 \% \text { de polpa cítrica } \\
50 \% \text { de polpa cítrica } \\
75 \% \text { de polpa cítrica }\end{array}$ & $\begin{array}{l}1,098 \\
1,159 \\
1,289 \\
1,173\end{array}$ & $\begin{array}{l}4,60 \\
4,69 \\
4,91 \\
4,76\end{array}$ & $\begin{array}{l}4,45 \\
4,24 \\
4,26 \\
4,43\end{array}$ & $\begin{array}{l}\text { Pereira et al. } \\
\quad(2008)\end{array}$ \\
\hline Casca de soja em dietas para ovinos & $\begin{array}{l}0 \% \text { de casca de soja } \\
8 \% \text { de casca de soja } \\
16 \% \text { de casca de soja } \\
18 \% \text { de casca de soja }\end{array}$ & $\begin{array}{l}1,200 \\
1,340 \\
1,300 \\
1,230\end{array}$ & $\begin{array}{l}- \\
- \\
- \\
-\end{array}$ & $\begin{array}{l}6,41 \\
5,81 \\
6,34 \\
6,25\end{array}$ & $\begin{array}{l}\text { Santos et al. } \\
\quad(2008)\end{array}$ \\
\hline
\end{tabular}


BORELLA, G. et al. Alimentação e grupo genético de ovinos terminados em confinamento: Revisão de literatura. PUBVET, Londrina, V. 5, N. 1, Ed. 148, Art. 995, 2011.

\subsection{Exigência de Energia}

Segundo Andriguetto et al. (1999) a energia de um alimento é medida em calorias, bem como as necessidades energéticas dos animais são expressas em calorias. O animal necessita de energia para manter a sua homeotermia, processos vitais do corpo, além das atividades físicas, incluindo aquelas associadas com a alimentação.

A produtividade dos ovinos depende, em grande parte, da ingestão abundante de elementos energéticos. Uma ração pobre em energia retarda, o crescimento, aumenta a idade à puberdade, reduz a fertilidade, diminui o ganho de peso e a produção de leite e, via de regra, os animais tornam-se menos resistentes às doenças e parasitas. Por outro lado, o fornecimento de energia além das necessidades para determinada condição conduz a acúmulos de gordura, podendo ocorrer desequilíbrio com os outros nutrientes, com prejuízo para a eficiência de produção (ESTRADA, 2000).

A exigência de energia para ganho significa que a quantidade deve ser fornecida ao animal para aumento no peso corporal (SANTOS, 2006).

As necessidades energéticas são diferentes para cada idade, raça ou estágio de desenvolvimento do rebanho. Siqueira (2008) mostrou que além destes fatores citados, outros fatores provocados por situações externas ao animal como: as condições do meio ambiente, tosquia e estresse (hídrico, alimentar e ambiental) e o tipo de sistema de criação adotado também influenciam nas necessidades energéticas de ovinos.

As exigências diárias de energia são calculadas pela soma das necessidades de mantença, atividade física, crescimento e engorda, gestação e lactação. As exigências de energia para mantença são aquelas necessárias para o metabolismo de um animal em jejum, sem haver perdas ou ganhos de tecido corporal ou produção de leite (ESTRADA, 2000).

Os animais criados em pasto apresentam gastos energéticos maiores que os animais criados em confinamento. Isto está diretamente ligado ao tipo e à disponibilidade de alimento e à quantidade e qualidade da água oferecida. No 
BORELLA, G. et al. Alimentação e grupo genético de ovinos terminados em confinamento: Revisão de literatura. PUBVET, Londrina, V. 5, N. 1, Ed. 148, Art. 995, 2011.

entanto, a distância percorrida diariamente pelos ovinos em pastagem, é maior, devido ao tamanho dos piquetes (SIQUEIRA, 2008).

De acordo com Sobrinho et al. (1996), em altos níveis de alimentação, a fração de energia metabolizável, que um ovino usa para atender a sua exigência básica de energia, raramente será menor que $40 \%$, mesmo quando o consumo é máximo.

Alves et al. (2003) estudaram diferentes níveis de energia em dietas para ovinos Santa Inês e verificaram efeito linear crescente com o aumento nos níveis de energia para o Consumo de matéria seca (CMS), coeficientes de digestibilidade aparente de matéria seca (CDAMS), matéria orgânica (CDAMO), extrato etéreo (CDAEE), carboidratos totais (CDACHOT) e não fibrosos (CDACNF); no entanto para os coeficientes de digestibilidade aparente do FDN (CDAFDN) e FDA (CDAFDA) observou-se efeito linear decrescente. Para coeficientes de digestibilidade aparente da Proteína bruta (CDAPB) não houve efeito com o aumento nos níveis de energia da dieta (Tabela 4).

Tabela 4: Médias, coeficiente de variação (CV), equação de regressão (ER), para os coeficientes de digestibilidade aparente de matéria seca (CDAMS), matéria orgânica (CDAMO), proteína bruta (CDAPB), extrato etéreo (CDAEE), carboidratos totais (CDACHOT) e não fibrosos (CDACNF), fibra em detergente neutro (CDAFDN) e fibra em detergente ácido (CDAFDA), em função dos níveis de energia metabolizável (EM) das dietas

\begin{tabular}{|c|c|c|c|c|c|}
\hline \multicolumn{6}{|c|}{ níveis de EM (Mcal/kg MS) } \\
\hline Variáveis & 2,42 & 2,66 & 2,83 & $(\mathrm{CV} \%)$ & ER \\
\hline CDAMS & 67,96 & 73,47 & 76,84 & 0,95 & $y=13,19005+22,57568$ EM** \\
\hline CDAMO & 70,04 & 75,72 & 78,99 & 0,63 & $y=-5,01866+30,07389 E M^{* *}$ \\
\hline CDAPB & 79,07 & 79,28 & 74,51 & 4,15 & $y=77,62$ \\
\hline CDAEE & 61,16 & 67,86 & 76,63 & 8,10 & $y=-31,48413+37,91173 E E^{* *}$ \\
\hline CDACHOT & 67,71 & 75,00 & 80,29 & 1,01 & $y=15,48878+22,52395$ EM** \\
\hline CDACNF & 81,03 & 92,34 & 96,16 & 3,50 & $y=-1,44446+34,59605 E E^{* *}$ \\
\hline CDAFDN & 63,65 & 61,54 & 53,95 & 7,81 & $y=98,59167-14,73492 E^{*} *$ \\
\hline CDAFDA & 55,51 & 52,91 & 38,04 & 16,96 & $y=120,19999-27,05136 E M *$ \\
\hline
\end{tabular}


BORELLA, G. et al. Alimentação e grupo genético de ovinos terminados em confinamento: Revisão de literatura. PUBVET, Londrina, V. 5, N. 1, Ed. 148, Art. 995, 2011.

Segundo Júnior et al. (2009) ao avaliarem as características quantitativas e a composição regional e tecidual de carcaças de cordeiros submetidos a três níveis de energia ( 2,$23 ; 2,54$ ou 2,85 Mcal de energia metabolizável/kg MS) na alimentação e abatidos aos $32,2 \pm 3,8 \mathrm{~kg}$ de peso corporal, observaram que 0 nível de energia teve efeito significativo nos pesos de paleta e pescoço e os maiores valores foram observados no nível intermediário, conforme demonstrado na Tabela 5.

Tabela 5: Pesos dos cortes $(\mathrm{kg})$ na meia-carcaça de cordeiros submetidos a três níveis de energia na alimentação onde é mostrado o coeficiente de variação (CV) e regressão

\begin{tabular}{lccccc}
\hline & \multicolumn{5}{c}{ Níveis de energia (Mcal de EM/kg MS) } \\
\hline Variável & 2,23 & 2,54 & 2,85 & CV $(\%)$ & Regressão \\
\hline Meia-carcaça & 7,265 & 7,588 & 6,871 & 9,37 & $\tilde{y}=7,241$ \\
Paleta & 1,363 & 1,789 & 1,251 & 10,57 & $\hat{y}=-27,83+23,48 X-4,66 \times 2$ \\
Perna & 2,294 & 2,250 & 2,199 & 10,60 & $\tilde{y}=2,248$ \\
Lombo & 0,900 & 0,903 & 0,883 & 14,37 & $\tilde{y}=0,895$ \\
Costela & 2,005 & 1,805 & 2,009 & 13,35 & $\tilde{y}=1,939$ \\
Pescoço & 0,702 & 0,840 & 0,526 & 13,40 & $\hat{y}=-12,71+10,94 X-2,21 X 2$ \\
\hline Adaptado de Júnior et al. (2009) & & \multicolumn{4}{l}{}
\end{tabular}

\subsection{Exigência de Proteína Bruta}

De acordo com Berchielli et al. (2006) as proteínas são macromoléculas presentes nas células com funções diversas, como componentes estruturais, funções enzimáticas, funções hormonais, recepção de estímulos hormonais e armazenamento de informações genética. São unidades formadoras de aminoácidos, unidos por ligações peptídicas. Sendo assim, a principal função das proteínas é construir ou reparar os tecidos que constituem os músculos, pele, órgãos internos, parte do tecido ósseo e nervoso (SANTOS, 2004).

A proteína é o principal constituinte do corpo animal e constantemente tem que ser suprida pela alimentação, para repor as células mortas e contribuir nos processos de síntese. A transformação da proteína de origem alimentar em proteína corporal ou proteína do leite é um importante processo 
BORELLA, G. et al. Alimentação e grupo genético de ovinos terminados em confinamento: Revisão de literatura. PUBVET, Londrina, V. 5, N. 1, Ed. 148, Art. 995, 2011.

de nutrição e metabolismo (ESTRADA, 2008).

Zundt et al. (2002) trabalhando com 32 cordeiros "tricross" (1/2 Texel + $1 / 4$ Bergamácia + 1/4 Corriedale) sendo 16 machos inteiros e 16 fêmas com idade média de 5 meses e peso corporal de $30 \mathrm{~kg}$, foram alimentados durante 57 dias com dietas isoenergéticas ( $72 \%$ NDT), variando os níveis protéicos (12, 16, 20 e 24 \% PB). A análise de variância revelou diferença significativa $(P=0,0742)$ para ganho de peso, indicando que houve efeito linear dos níveis protéicos. A equação de regressão ajustada ( $\left.Y^{\wedge}=0,1361+0,0015 x\right)$ para ganho de peso mostra aumento de $0,0015 \mathrm{~kg} /$ dia para cada $1 \%$ de aumento no nível de proteína dietética. Os valores de ganho de peso estimados de acordo com a equação de regressão para os níveis de 12, 16, 20 e 24\% de PB são, respectivamente: 0,154;0,160;0,166; e 0,172 kg.

Rocha et al. (2004) avaliaram a influência de teores de proteína bruta (PB) em dietas com alta proporção de concentrado sobre o desempenho e características de carcaça de cordeiros deslanados, confinados por 56 dias. As dietas experimentais continham $80 \%$ concentrado e $20 \%$ de bagaço de canade-açúcar, com teores de 14,16, 18 ou $20 \%$ PB na matéria seca. Não houve diferença entre os tratamentos para ganho de peso, consumo de matéria seca e conversão alimentar, conforme demonstrado na Tabela 6.

Tabela 6: Peso inicial e final, ganho médio diário (GMD), consumo de matéria seca (CMS) e conversão alimentar (CA) em diferentes níveis de PB para ovinos confinados.

\begin{tabular}{lcccc}
\hline Característica & $14 \% \mathrm{~PB}$ & $16 \% \mathrm{~PB}$ & $18 \% \mathrm{~PB}$ & $20 \% \mathrm{~PB}$ \\
\hline PI $(\mathrm{kg})$ & 18,0 & 18,4 & 18,5 & 18,6 \\
PF (kg) & 30,8 & 30,7 & 31,4 & 31,5 \\
GMD (g/dia) & 228 & 220 & 230 & 231 \\
CMS (kg/dia) & 1,035 & 1,022 & 1,083 & 1,103 \\
CA (kg MS/kg ganho) & 4,19 & 4,28 & 4,35 & 4,44 \\
\hline
\end{tabular}

Adaptado de Rocha et al. (2004). 
BORELLA, G. et al. Alimentação e grupo genético de ovinos terminados em confinamento: Revisão de literatura. PUBVET, Londrina, V. 5, N. 1, Ed. 148, Art. 995, 2011.

\subsection{Dieta e manejo nutricional}

A alimentação é um item de grande importância na terminação de cordeiros, sendo que é através dela que os nutrientes são conduzidos para o organismo dos animais, e estes bem alimentados podem expressar seu potencial de produção (RIBEIRO, 1997).

Segundo Pinheiro et al. (2009), os ingredientes da dieta de ruminantes confinados são normalmente constituídos por alimentos concentrados e volumosos. Os concentrados são responsáveis pelo maior custo da alimentação dos ovinos mantidos neste sistema de produção, normalmente os volumosos apresentam preços mais acessíveis e podem proporcionar bom desempenho animal dependendo qualidade nutricional.

Segundo Gomes (2001) citado por Simplício et al. (2002), no sistema de confinamento, é essencial a alimentação volumosa e concentrada de alta qualidade e o ano todo, aumentado a complexidade do sistema a medida que se deve produzir ou comprar grandes quantidades de alimentos. Isto representa maior risco para o produtor diante de alterações dos preços relativos de produtos e insumos, uma vez que o sistema é mais sensível à mudanças de preços relativos. Numa economia historicamente instável, como a do Brasil, isto representa um sério problema, visto que o preço de sobrevivência desse sistema é mais elevado em relação aos demais.

A mineralização deve ser feita com sal mineral à vontade, específico para ovinos, em cochos separados, dos de alimentação. As misturas minerais comerciais, específicas para ovinos, geralmente são compostas de sal iodado e macro e micronutrientes (fósforo, cálcio, cobalto, zinco, cobre e outros) (BENDAHAN e BRAGA, 2005).

\subsubsection{Alimento Concentrado}

O concentrado é constituído basicamente de grãos de cereais, divididos em protéicos e energéticos como (grão de milho, grão de milheto, grão de 
BORELLA, G. et al. Alimentação e grupo genético de ovinos terminados em confinamento: Revisão de literatura. PUBVET, Londrina, V. 5, N. 1, Ed. 148, Art. 995, 2011.

sorgo, farelo de soja, caroço de algodão, entre outros). Esta ração concentrada deve ser balanceada e com teores de energia e proteína para suprirem as exigências do animal de acordo com sua idade (SANTOS, 2004).

De acordo com Ribeiro (1997), os alimentos concentrados possuem menos de $18 \%$ de fibra bruta, sendo considerados energéticos os que apresentam menos de $20 \%$ de $\mathrm{PB}$, ou protéicos quando apresentarem mais de $20 \%$ de PB. O alimento concentrado apresenta maior concentração de nutrientes em relação ao volumoso, e animais com exigências elevadas não conseguem ingerir a quantidade de nutrientes necessários se receberem somente o alimento volumoso, por isso, a importância de se fornecer o concentrado também.

Sobrinho et al. (2002) trabalharam com efeito da relação volumoso: concentrado e o peso ao abate sobre os componentes da perna da perna de cordeiro Ile de France $x$ Ideal confinados utilizando 20 cordeiros deste cruzamento com peso médio de entrada $18,2 \mathrm{~kg}$, com uma relação de 50V:50C e 30V:70C, verificaram que os animais que consumiram a ração com relação 30V:70C apresentaram maior porcentagem de gordura subcutânea e gordura intermuscular em relação aos que receberam relação 50V: 50C.

Resultados encontrados por Medeiros et al. (2007) para avaliação dos níveis de concentrado sobre o desempenho de ovinos Morada Nova em confinamento utilizando dietas contendo 20,40, 60 e $80 \%$ de concentrado, indicaram que não houve efeito do nível de concentrado sobre o peso ao abate, bem como para o ganho de peso total durante o confinamento. 0 consumo total de MS diminuiu de 111,50 para $56,74 \mathrm{~kg}$, quando utilizadas dietas de 20 e $80 \%$ de concentrado. O consumo de MS expressos em kg/dia, em porcentagem (\%), em $\mathrm{g} / \mathrm{kg} \mathrm{PV} /$ dia e em gramas por unidade de peso metabólico ( $\mathrm{g} M S / \mathrm{PV}^{0,75}$ ) foram crescentes em relação aos níveis de concentrado. Observou-se também efeito linear em relação ao ganho de peso diário, aumentando o ganho de peso conforme o aumento do concentrado na dieta. A conversão alimentar melhorou linearmente com o nível de concentrado na dieta (Tabela 7). 
BORELLA, G. et al. Alimentação e grupo genético de ovinos terminados em confinamento:

Revisão de literatura. PUBVET, Londrina, V. 5, N. 1, Ed. 148, Art. 995, 2011.

Tabela 7: Desempenho de ovinos Morada Nova alimentados com dietas com diferentes níveis de concentrados.

\begin{tabular}{|c|c|c|c|c|c|c|}
\hline \multicolumn{7}{|c|}{ Nível de Concentrado (\%) } \\
\hline & 20 & 40 & 60 & 80 & $\mathrm{CV}(\%)$ & regressão \\
\hline PV inicial $(\mathrm{kg})$ & 20,37 & 19,42 & 19,0 & 19,92 & - & - \\
\hline PV abate $(\mathrm{kg})$ & 30,92 & 30,68 & 30,42 & 30,84 & 3,28 & $\hat{y}=30,71^{\mathrm{ns}}$ \\
\hline Dias de confina & $\begin{array}{c}123,3 \\
7\end{array}$ & 86,62 & 75,25 & 52,50 & 34,58 & $\begin{array}{c}\hat{y}=140,438- \\
1,12 * C^{1}\end{array}$ \\
\hline CMS total $(\mathrm{kg})$ & $\begin{array}{c}111,5 \\
0\end{array}$ & 82,22 & 70,62 & 56,74 & 25,83 & $\begin{array}{c}\hat{y}=124,245- \\
0,879408^{*} C\end{array}$ \\
\hline CMS (kg/dia) & 0,925 & 0,964 & 1,003 & 1,124 & 13,14 & $\begin{array}{l}\hat{y}=0,84478+ \\
0,00319125^{*} \mathrm{C}\end{array}$ \\
\hline CMS (\%) & 3,63 & 3,83 & 4,01 & 4,45 & 9,74 & $\begin{array}{c}\hat{y}=3,32047+ \\
0,0132902 * C\end{array}$ \\
\hline g MS/kg PC/dia & 36,32 & 38,35 & 40,13 & 44,58 & 9,74 & $\begin{array}{c}\hat{y}=33,2047+ \\
0,132902 * \mathrm{C}\end{array}$ \\
\hline $\begin{array}{l}\text { g MS/kg PC } \\
0,75 / \mathrm{dia}\end{array}$ & 81,55 & 85,84 & 89,69 & 99,88 & 10,189 & $\begin{array}{c}\hat{y}=74,5332+ \\
0,294191 * C\end{array}$ \\
\hline GPT $(\mathrm{kg})$ & 10,54 & 11,25 & 11,42 & 10,91 & 9,66 & $\hat{y}=11,0^{n s}$ \\
\hline GPD (kg) & 0,089 & 0,134 & 0,168 & 0,224 & 28,59 & $\begin{array}{c}\hat{y}=0,044331+ \\
0,0021982 * C\end{array}$ \\
\hline $\begin{array}{l}\text { CA (kg MS/ kg } \\
\text { GMD) }\end{array}$ & 10,51 & 7,32 & 6,03 & 5,09 & 22,59 & $\begin{array}{c}\hat{y}=11,9866- \\
0,090517 * C\end{array}$ \\
\hline Ef. alimentar (\%) & 9,86 & 14,46 & 17,16 & 20,35 & 22,59 & $\begin{array}{c}\hat{y}=6,91733+ \\
0,170812^{*} \mathrm{C}\end{array}$ \\
\hline
\end{tabular}

1 Nível de concentrado

* Significativo a 1 e $5 \%$ de probabilidade pelo teste $t$; ns - não-significativo

Adaptado de Medeiros et al. (2007)

\subsubsection{Alimento Volumoso}

Engloba todos os alimentos de baixo valor energético por unidade de peso, devido ao seu elevado teor de fibra bruta ou em água. Sendo assim, são considerados alimentos volumosos todos aqueles que apresentam mais de 18 $\%$ de fibra bruta (ANDRIGUETTO et al., 1999).

O volumoso pode ser o feno de leguminosa, capim elefante picado, silagem de sorgo, de milho entre outros (SANTOS, 2004). Neste caso, Siqueira (2008) salientou que o consumo médio diário deve ser de aproximadamente $4 \%$ do peso vivo do animal em matéria seca, ingerindo $800 \mathrm{~g}$ de matéria 
BORELLA, G. et al. Alimentação e grupo genético de ovinos terminados em confinamento: Revisão de literatura. PUBVET, Londrina, V. 5, N. 1, Ed. 148, Art. 995, 2011.

seca/dia para obter um ganho médio diário na faixa de 200 a $400 \mathrm{~g} /$ dia.

De um modo geral, como volumosos, os fenos sendo eles de boa qualidade, são os mais indicados para serem utilizados na terminação de cordeiros em confinamento. Mas, é importante ressaltar que a escolha do tipo de volumoso a ser utilizada deverá sempre ser analisada também do ponto de vista econômico (GERASEEVet al., 2009). No entanto, para uma exploração racional da ovinocultura é essencial a conservação de alimentos produzidos na "época das águas", para uso no período de escassez (BUENO et al., 2007).

A capacidade de digestão e o aproveitamento de forragem irão depender da eficiência de seu desempenho e da qualidade nutricional das forragens ou outros materiais fibrosos oferecidos como parte maior da dieta. Pesquisas realizadas em várias espécies ruminantes mostram que o ideal é o fornecimento mínimo de 50 a $70 \%$ da MS da dieta na forma de volumoso (OLIVEIRA, 2008).

Carvalho et al. (2007) ao avaliarem o desempenho e viabilidade econômica da alimentação de cordeiros confinados com dietas contendo diferentes relações de volumoso: concentrado verificaram que o aumento da concentração do volumoso promoveu uma redução linear no ganho de peso dos cordeiros. Em relação ao consumo de matéria seca, observaram que a ingestão de alimentos foi limitada pelos enchimentos para os níveis de 50, 60 e $70 \%$ de volumoso, enquanto que a inclusão de volumoso inferior a $40 \%$ levou à regulação fisiológica do consumo. Ainda para conversão alimentar, aferiram que o melhor valor foi obtido para os cordeiros alimentados com dieta contendo $30 \%$ volumoso e $70 \%$ concentrado apresentando conversão alimentar de 4,02. Em relação a venda das carcaças dos cordeiros, verificaram que a mesma diminui com o aumento do teor de volumoso devido ao peso da carcaça verificada no abate (Tabela 8 ). 
BORELLA, G. et al. Alimentação e grupo genético de ovinos terminados em confinamento: Revisão de literatura. PUBVET, Londrina, V. 5, N. 1, Ed. 148, Art. 995, 2011.

Tabela 8: Valores médios do peso vivo inicial (PVI), peso de abate (PA), ganho médio diário total (GMDT), consumo de matéria seca (CMS), conversão alimentar (CA), peso da carcaça quente (PCQ), rendimento de carcaça quente (RCQ), despesas diárias com feno (DDF), despesas diárias com o concentrado (DDC), despesas diárias totais (DDT) e despesas totais (DT), receita bruta em relação as carcaças (RC) e o lucro em relação as carcaças (LC) de acordo com os tratamentos

\begin{tabular}{|c|c|c|c|c|c|c|c|}
\hline \multicolumn{8}{|c|}{ Relação Volumoso: Concentrado } \\
\hline & $30: 70$ & $40: 60$ & $50: 50$ & $60: 40$ & $70: 30$ & CV (\%) & ER \\
\hline PVI (kg) & 15,93 & 17,64 & 17,00 & 17,60 & 16,56 & 20,90 & $Y=16,94$ \\
\hline PA $(\mathrm{kg})$ & 34,13 & 32,60 & 28,82 & 27,02 & 26,08 & 13,56 & 1 \\
\hline GMDT (kg/dia) & 0,228 & 0,187 & 0,148 & 0,123 & 0,119 & 15,53 & 2 \\
\hline CMS (kg/dia) & 0,910 & 0,955 & 0,841 & 0,662 & 0,579 & 5,05 & 3 \\
\hline $\mathrm{CA}$ & 4,02 & 5,19 & 5,81 & 5,52 & 5,02 & 16,84 & 4 \\
\hline PCQ $(\mathrm{kg})$ & 14,59 & 14,58 & 12,42 & 10,80 & 10,55 & 16,74 & 5 \\
\hline RCQ (\%) & 42,72 & 44,93 & 43,17 & 39,80 & 40,51 & 5,31 & 6 \\
\hline DDF (R\$/an/dia) & 0,10 & 0,15 & 0,16 & 0,15 & 0,15 & 5,28 & 4 \\
\hline DDC (R\$/an/dia) & 0,37 & 0,35 & 0,26 & 0,17 & 0,11 & 7,06 & 5 \\
\hline DDT (R\$/an/dia) & 0,47 & 0,50 & 0,42 & 0,32 & 0,27 & 6,29 & 6 \\
\hline DT ( R\$/an) & 37,40 & 39,76 & 3,84 & 25,45 & 21,30 & 6,18 & 7 \\
\hline $\mathrm{RC}(\mathrm{R} \$ / \mathrm{an})$ & 138,57 & 138,53 & 117,91 & 102,60 & 100,16 & 16,74 & 9 \\
\hline LC (R\$/an) & 101,18 & 98,77 & 84,07 & 77,15 & 78,85 & 22,43 & 10 \\
\hline \multicolumn{8}{|c|}{ 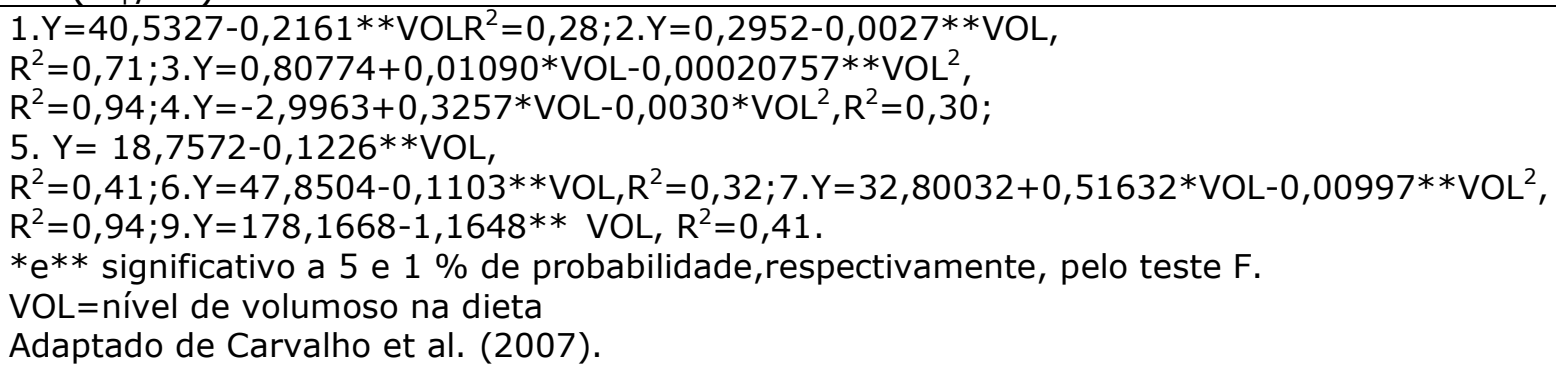 } \\
\hline
\end{tabular}

Pinto et al. (2005) objetivaram avaliar o desempenho de cordeiros Santa Inês terminados com diferentes fontes de volumosos em confinamento. Os tratamentos foram: $\mathrm{T} 1=60 \%$ feno de capim d'água (Panicum geminatum) + $40 \%$ de concentrado; $\mathrm{T} 2=60 \%$ feno de restolho de abacaxi (Ananas comosus $)+40 \%$ de concentrado; e T3 $=60 \%$ silagem composta de milho (Zea mays) e capim d'água (Panicum geminatum) $+40 \%$ de concentrado. Foi observado efeito das dietas sobre o ganho médio de peso diário, constatandose que os animais que receberam o feno de restolho de abacaxi como volumoso na dieta apresentaram melhor desempenho, sugerindo que, 
BORELLA, G. et al. Alimentação e grupo genético de ovinos terminados em confinamento: Revisão de literatura. PUBVET, Londrina, V. 5, N. 1, Ed. 148, Art. 995, 2011.

provavelmente, o menor teor de lignina e maior teor de pectina do restolho de abacaxi sugere que este alimento volumoso possui maior digestibilidade e provavelmente maior teor de energia quando comparados aos outros alimentos testados. Registrou-se maior consumo diário de matéria seca ( $\mathrm{kg} / \mathrm{dia}$ e \% PC) para os animais que receberam como volumoso o feno de capim d'água, entretanto, o menor ganho de peso registrado neste tratamento proporcionou pior conversão alimentar, provavelmente, devido a baixa digestibilidade do feno, pois, o material fenado encontrava-se em avançado estado de maturação (Tabela 9).

Tabela 9: Médias de características relacionadas ao desempenho em cordeiros Santa Inês, terminados em confinamento, alimentados com diferentes volumosos

\begin{tabular}{lccc}
\hline \multicolumn{3}{c}{ Tratamentos } & \\
\hline Características & $\mathrm{T} 1$ & $\mathrm{~T} 2$ & $\mathrm{~T} 3$ \\
\hline Idade ao abate (dias) & $278,75^{\mathrm{a}}$ & $241,50^{\mathrm{b}}$ & $247,50^{\mathrm{ab}}$ \\
Duração do experimento (dias) & $98,00^{\mathrm{a}}$ & $63,00^{\mathrm{c}}$ & $80,50^{\mathrm{b}}$ \\
PV abate (kg) & $29,25^{\mathrm{a}}$ & $30,05^{\mathrm{a}}$ & $29,77^{\mathrm{a}}$ \\
GP total (kg) & $8,31^{\mathrm{a}}$ & $8,81^{\mathrm{a}}$ & $8,12^{\mathrm{a}}$ \\
Consumo MS (\% PC) & $6,47^{\mathrm{a}}$ & $4,84^{\mathrm{b}}$ & $4,09^{\mathrm{c}}$ \\
Consumo MS (kg/dia) & $1,89^{\mathrm{a}}$ & $1,38^{\mathrm{b}}$ & $1,20^{\mathrm{c}}$ \\
GP médio diário (kg/dia) & $0,09^{\mathrm{b}}$ & $0,14^{\mathrm{a}}$ & $0,10^{\mathrm{b}}$ \\
Conversão alimentar $(\mathrm{kg})$ & $22,68^{\mathrm{a}}$ & $10,15^{\mathrm{b}}$ & $12,37^{\mathrm{b}}$ \\
\hline
\end{tabular}

$\mathrm{T} 1=60 \%$ feno de capim d'água (Panicum geminatum) $+40 \%$ de concentrado;

$\mathrm{T} 2=60 \%$ feno de restolho de abacaxi (Ananas comosus) $+40 \%$ de concentrado;

$\mathrm{T} 3=60 \%$ silagem composta de milho (Zea mays) e capim d'água (Panicum geminatum) + $40 \%$ de concentrado.

Adaptado de Pinto et al. (2005).

\subsection{Peso, idade de abate e características de carcaça}

Quando se trabalha com ovinos destinados à produção de carne, é necessária a determinação do peso ideal de abate, o que permitirá maior produtividade e o encontro das exigências dos consumidores. Para atingir estes objetivos, o estudo do desenvolvimento relativo dos cortes da carcaça, que são as partes mais comercializadas, é importante. O crescimento das regiões da carcaça, assim como a determinação do ritmo de crescimento de cada 
BORELLA, G. et al. Alimentação e grupo genético de ovinos terminados em confinamento: Revisão de literatura. PUBVET, Londrina, V. 5, N. 1, Ed. 148, Art. 995, 2011.

constituinte corporal, são informações importantes para a eficiência da produção, pois à medida que o animal cresce, acontecem modificações nas suas proporções corporais (SANTOS, 2003).

O excesso de gordura, como conseqüência de pesos de abate inadequados, afeta a qualidade do produto final. Pires et al. (1999) salientaram que à medida que aumenta a idade dos animais, as diferenças relativas de espessura de gordura subcutânea, aumentaram.

A quantidade de gordura é o principal fator determinante do peso ideal de abate, que pode variar de acordo com a genética e o sistema de alimentação. Podendo variar também de acordo com o animal (SIQUEIRA, 2008).

A idade do animal é um dos fatores que influencia na cor, quantidade e distribuição de gordura depositada na carcaça e na carne ovina. Monteiro (2002) afirmou que animais mais velhos tem uma tendência de apresentar camada mais espessa de gordura e coloração mais escura na carne. No entanto, a deposição de gordura na carcaça e na carne é também influenciada pela raça, sexo e a alimentação.

Em relação a conversão alimentar, animais mais jovens apresentam melhor valor desta, quando comparados a animais mais velhos, e também é mais vantajoso confinar cordeiros ao invés de animais erados, justamente por apresentarem qualidade de carcaça superior (SANTOS, 2004).

Vasconcelos et al. (2000) sugeriram que o acabamento de cordeiros em confinamento deve ser iniciado quando os animais atingem peso corporal mínimo de $15 \mathrm{~kg}$ e deve ter a duração de 56 a 70 dias de confinamento. Para Bendahan e Braga (2005), o produtor poderá abater animais entre 4 e 6 meses com 30 a $35 \mathrm{~kg}$, em média, dependendo da qualidade genética dos animais.

Cordeiros desmamados precocemente com idade entre 50 e 60 dias, são muito exigentes em nutrientes, principalmente em energia e proteína. O acabamento é feito com peso inicial (desmama) de 14-16 kg, até um peso final (acabamento) de 30 a $35 \mathrm{~kg}$, com ganhos diários de peso acima de $250 \mathrm{~g} / \mathrm{dia}$. Todavia, esse ganho pode alcançar mais de $400 \mathrm{~g} / \mathrm{dia}$, em animais 
BORELLA, G. et al. Alimentação e grupo genético de ovinos terminados em confinamento: Revisão de literatura. PUBVET, Londrina, V. 5, N. 1, Ed. 148, Art. 995, 2011.

especializados para a produção de carne. A conversão alimentar, nesta categoria fica próximo de 3-3,5:1, sendo, portanto, excelentes transformadores de alimento de origem vegetal, em carne nobre (BUENO et al., 2007).

Macedo et al. (1999) ao avaliar o desempenho de cordeiros Corriedale, puros e mestiços, terminados em pastagem e em confinamento, abatidos com $30-32 \mathrm{~kg}$ de peso vivo na origem, observaram que o ganho de peso da desmama ao abate foi maior para os cordeiros em confinamento $(0,144 \mathrm{~kg})$ do que para os terminados em pastagem $(0,106 \mathrm{~kg})$, apesar de ambos terem sido alimentados com dieta de composição química similar. Os sistemas de terminação e de cruzamento influenciaram a idade de abate. Cordeiros em confinamento atingiram peso de abate em idades menores (219 dias) que os terminados em pastagem (258 dias). O menor tempo para os cordeiros confinados atingirem peso de abate pode ser atribuído também à menor infestação com helmintos parasitas (Tabela 10).

Tabela 10: Médias estimadas dos pesos na origem (PO) e ao abate (PA) e porcentagem de perdas (PP) de acordo com o sistema de terminação

\begin{tabular}{lcc}
\hline & \multicolumn{3}{c}{ Terminação } \\
\cline { 2 - 3 } Variável & Pasto & Confinamento \\
\hline PO $(\mathrm{kg})$ & 31,40 & 31,36 \\
PA $(\mathrm{kg})$ & 29,61 & 30,36 \\
PP $(\%)$ & $5,17 \mathrm{~b}$ & $3,16 \mathrm{a}$ \\
\hline
\end{tabular}

Médias na mesma linha seguidas de letras diferentes diferem entre si pelo teste de Tukey $(P<0,5)$. Fonte: Macedo et al. (1999)

Em relação às características de carcaça, os ovinos apresentam características produtivas diferentes dos bovinos, tendo melhor qualidade de carne, e eficiência de produção decorrente de sua alta velocidade de crescimento, as quais devem ser valorizadas para aumentar a produção de carne. Entretanto, no Brasil e especialmente no Nordeste, a produção e comercialização da carne ovina ainda encontram-se desorganizadas, apresentando baixa oferta, assim, prejudicando o crescimento no consumo 
BORELLA, G. et al. Alimentação e grupo genético de ovinos terminados em confinamento: Revisão de literatura. PUBVET, Londrina, V. 5, N. 1, Ed. 148, Art. 995, 2011.

(CUNHA et al., 2008).

O custo de mantença dos animais, a conformação e a composição da carcaça são pontos muito importantes e devem ser considerados quando se programa fazer a introdução de uma nova raça de corte para a exploração em estado de pureza racial ou de suas cruzas, uma vez que as duas últimas características influenciam, de forma significativa, o rendimento da carcaça e a qualidade da carne e, à primeira, o retorno econômico do sistema de exploração (SIMPLICIO et al., 2002).

Assim como o ganho de peso, o rendimento de carcaça é um parâmetro importante na avaliação dos animais. O rendimento está relacionado de forma direta à comercialização de cordeiro, devido a ser um dos primeiros índices a ser considerado, expressando o peso vivo do animal e o da carcaça (PILAR et al., 2002).

Segundo Bueno et al. (2000), a padronização das carcaças de cordeiros a serem colocadas no mercado é necessária para valorizar o produto e atrair o consumidor. As carcaças devem apresentar elevada porcentagem de músculos, cobertura de gordura subcutânea uniforme e teor de gordura adequado ao mercado consumidor, características definidas pelo grau de maturidade do genótipo. Importante afirmar também, que o consumidor tem preferência por carcaças de tamanho moderado entre $12-14 \mathrm{~kg}$, o que determina o abate dos animais entre $28-30 \mathrm{~kg}$ de peso corporal.

De acordo com Siqueira (2008), o rendimento de carcaça no abate de cordeiros de 30 a $35 \mathrm{~kg}$ está em média, entre 42 e $45 \%$. O aumento do peso de abate pode elevar o rendimento dessas. Porém, rendimentos muito altos podem estar associados ao excessivo grau de gordura.

Bueno et al., (2000) trabalharam na avaliação de características de cordeiros Suffolk abatidos em diferentes idades, observaram que os cortes, quando expressos em porcentagem da carcaça fria, mostram variações devido ao aumento da idade dos animais. Observaram diminuição do traseiro, aumento do costilhar e não-alteração do dianteiro, mostrando que o aumento da idade de abate leva à diminuição da parte mais nobre da carcaça que é o 
BORELLA, G. et al. Alimentação e grupo genético de ovinos terminados em confinamento: Revisão de literatura. PUBVET, Londrina, V. 5, N. 1, Ed. 148, Art. 995, 2011.

traseiro.

Sobrinho et al. (2005) avaliaram características da qualidade da carne de ovinos de diferentes genótipos e idade de abate com três raças paternas (Romney, East Friesian x (Finn x Texel) e Finn x Poll Dorset) verificaram que as características de qualidade de carne dos três grupos genéticos não diferiram para pH final, líquido exsudado, comprimento do sarcômero, parâmentro de cor e porcentagem de perda no cozimento. A idade de abate dos cordeiros afetaram o $\mathrm{pH}$ e a cor da carne.

De acordo com os resultados encontrados por Monteiro et al. (2000) o cruzamento Ile de France $x$ Corriedale imprimiu efeito nas variáveis de peso vivo dos cordeiros e das carcaças e na área de lombo. Para o teor de lipídeos totais no Longissimus dorsi e o rendimento de carcaça, não foram observadas diferenças significativas entre os dois grupos (Tabela 11).

Tabela 11: Valores médios e desvio padrão dos parâmetros quantitativos das carcaças dos cordeiros

\begin{tabular}{lccc}
\hline Variáveis & Corriedale & Cruza $($ IF $\times$ C) & Significância \\
\hline Peso vivo dos cordeiros $(\mathrm{kg})$ & 26,42 & 33,08 & $0,0001^{*}$ \\
Peso de carcaça quente $(\mathrm{kg})$ & 10,09 & 12,66 & $0,0001^{*}$ \\
Rendimento d e caracaça $(\%)$ & 38,08 & 38,10 & $\mathrm{~ns}$ \\
Área de Lombo $\left(\mathrm{cm}^{2}\right)$ & 7,32 & 10,29 & $0,0008^{* *}$ \\
Lipídeos totais $(\mathrm{g} \%)$ & 2,12 & 2,13 & $\mathrm{~ns}$ \\
\hline
\end{tabular}

* $\mathrm{P}<0,0001, * * \mathrm{P}<0,0008$ e ns (não significativo).

Adaptado de Monteiro et al. (2000).

Oliveira et al. (2007) avaliaram diferentes pesos de abate de cordeiros confinados e observaram uma maior taxa de ganho médio diário (GMD) para os animais abatidos aos $35 \mathrm{~kg}$ de peso vivo. Este resultado, possivelmente, está relacionado ao fato destes animais apresentarem, numericamente, maior peso ao início do experimento, o que pode indicar uma maior adaptabilidade destes à ingestão de alimento sólido, evidenciada pelo maior consumo de matéria seca em proporção ao peso corporal. Desta forma, o número de dias necessários para que os animais atingissem os pesos de abate não aumentou de maneira proporcional ao aumento do peso corporal (Tabela 12). 
BORELLA, G. et al. Alimentação e grupo genético de ovinos terminados em confinamento:

Revisão de literatura. PUBVET, Londrina, V. 5, N. 1, Ed. 148, Art. 995, 2011.

Tabela 12. Valores médios e coeficientes de variação para peso inicial, peso ao abate, ganho médio diário (GMD), dias necessários para atingir o peso de abate, consumo de matéria seca e peso de carcaça fria, de acordo com o peso de abate pretendido

\begin{tabular}{lcccc}
\hline \multicolumn{5}{c}{ Peso de abate } \\
\hline Variáveis & 25 & 30 & 35 & Média \\
\hline Peso inicial $(\mathrm{kg})$ & 17,870 & 17,420 & 18,280 & 17,860 \\
Peso ao abate $(\mathrm{kg})$ & $25,520^{\mathrm{A}}$ & $30,620^{\mathrm{B}}$ & $35,440^{\mathrm{C}}$ & 30,530 \\
GMD (kg/dia) & $0,218^{\mathrm{B}}$ & $0,244^{\mathrm{AB}}$ & $0,267^{\mathrm{A}}$ & 0,243 \\
Dias até o abate & $35,39^{\mathrm{A}}$ & $53,73^{\mathrm{B}}$ & $65,23^{\mathrm{C}}$ & 51,12 \\
CMS (kg/dia) & $0,627^{\mathrm{A}}$ & $0,699^{\mathrm{B}}$ & $0,847^{\mathrm{C}}$ & 0,725 \\
CMS (\%PV) & $2,89^{\mathrm{B}}$ & $2,91^{\mathrm{B}}$ & $3,16^{\mathrm{A}}$ & 2,98 \\
CMS total $(\mathrm{kg})$ & $22,18^{\mathrm{A}}$ & $36,51^{\mathrm{B}}$ & $55,52^{\mathrm{C}}$ & 38,07 \\
Peso de carcaça fria $(\mathrm{kg})$ & $11,105^{\mathrm{C}}$ & $13,953^{\mathrm{B}}$ & $16,014^{\mathrm{A}}$ & 13,551 \\
\hline
\end{tabular}

Letras diferentes na linha indicam diferenças significativas pelo teste de Tukey $(P<0,05)$.

Adaptado de Oliveira et al. (2007)

\subsection{Grupo genético}

No Brasil existe uma grande variedade de espécies ovinas para produção de carne. Geralmente a fêmea é de dupla aptidão (lã e carne) ou ovelhas SRD (sem raça definida), acasaladas com reprodutores especializados para carne. Sendo assim, as fêmeas precisam ser adaptadas ao ambiente, com boa habilidade materna (alta produção de leite), e os machos precisam ser bem selecionados para velocidade de crescimento, conversão alimentar e boas características de carcaça, só assim os produtos serão bons para o confinamento (Santos, 2004).

As principais raças de ovinos de corte indicadas para utilização no Brasil são Santa Inês, Morada Nova, Somalis Brasileira, Dorper, Rabo Largo, Cariri e SRD (Leite et al., 2005). As raças especializadas na produção de carne são mais exigentes em termos de nutrição e ambiente em geral, adaptando-se melhor a criações mais intensificadas.

As principais raças paternais utilizadas em cruzamentos viabilizando a produção de carne são: Dorper, Ile de France, Texel, Suffolk, Hampshire Down, Poll Dorset. 
BORELLA, G. et al. Alimentação e grupo genético de ovinos terminados em confinamento:

Revisão de literatura. PUBVET, Londrina, V. 5, N. 1, Ed. 148, Art. 995, 2011.

Tabela 14. Médias de peso corporal (PC) entre pesagens de cordeiros de 5 genótipos

\begin{tabular}{|c|c|c|c|c|c|}
\hline Peso & & Raçá & & & \\
\hline & Texel & Romney & Corriedale & Ideal & Merino \\
\hline $\mathrm{PC}(\mathrm{kg})$ & & & & & \\
\hline PN & 4,6 & 4,4 & 3,9 & 3,7 & 4,0 \\
\hline PD (75 dias) & 21,8 & 18,3 & 15,6 & 15,0 & 16,7 \\
\hline P6 (120 dias) & 24,9 & 20,9 & 17,5 & 17,5 & 18,6 \\
\hline P10 (170 dias) & 30,8 & 25,1 & 21,5 & 20,9 & 21,4 \\
\hline PPA (225 dias) & 33,0 & 26,2 & 23,3 & 23,5 & 22,7 \\
\hline GPT (kg) & & & & & \\
\hline PD-PN (75) & 17,2 & 13,9 & 11,7 & 11,3 & 12,7 \\
\hline P6-PD (45) & 3,1 & 2,6 & 1,9 & 2,5 & 1,9 \\
\hline P10-P6 (50) & 5,9 & 4,2 & 4,0 & 3,4 & 2,8 \\
\hline PPA-P10 (55) & 2,2 & 1,1 & 1,8 & 2,6 & 1,3 \\
\hline
\end{tabular}

Adaptado de Oliveira, Osório e Monteiro (1996)

\section{CONSIDERAÇÕES FINAIS}

O confinamento de ovinos, é sem dúvida uma importante alternativa para incrementar a oferta regular do produto, agilizando o retorno do capital aplicado, permitindo a produção de carne de qualidade durante todo o ano, e ainda produzir alimentos padronizados através da idade reduzida entre 4 e 6 meses de idade.

A utilização desse sistema é puramente econômica, em que fatores como, velocidade de acabamento, conversão alimentar, qualidade dos animais disponíveis, preço e qualidade da alimentação e mercado demandador de carnes de qualidade, devem ser levados em conta sistematicamente, para que o produtor obtenha ganho econômico na atividade.

A alimentação sendo o fator de maior importância neste sistema deve ser preparada de acordo com as exigências do animal e ser programada para o período de escassez de alimento.

O mercado nacional de ovinos busca cada vez mais produtos e empresas que ofereçam, acima de tudo, qualidade e o criador tem o desafio de 
BORELLA, G. et al. Alimentação e grupo genético de ovinos terminados em confinamento: Revisão de literatura. PUBVET, Londrina, V. 5, N. 1, Ed. 148, Art. 995, 2011.

incrementar seu negócio, investindo em genética também e estando atento às transformações do mercado que possam agregar valor na sua criação.

\section{REFERÊNCIAS}

ALVES, K. S, CARVALHO, F. F.R, VÉRAS, A. S. C. et al. Níveis de energia em dietas para ovinos Santa Inês: Digestibilidade aparente. Revista Brasileira de Zootecnia, v.32, n.6, p.1962-1968, 2003.

ALVES, K. S, CARVALHO, F. F. R. FERREIRA, M. A, et al. Níveis de energia em dietas para ovinos $S$ anta Inês: características de carcaça e constituintes corporais. Revista Brasileira de Zootecnia, v.32, n.6, p.1927-1936, 2003.

ANDRIgUetTO, J. M. et al. Nutrição Animal. Editora Nobel, São Paulo-SP, v.1, 395 p, 1999.

BARROS, N. N. VASCONCELOS, V. R. ARAÚJO, M. R. A, et al. Influência do grupo genético e da alimentação sobre o desempenho de cordeiros em confinamento. Pesq. agropecuária brasileira, Brasília, v. 38, n. 9, p. 1111-1116, set. 2003.

BARROS, C.S. MONTEIRO, A.L.G. POLI, C.H.E.C, et al. Resultado econôminco da produção de ovinos para carne em pasto de azevém e confinamento. DOI: 10.4025/actascianimsci. v31i1.3995, 2009.

BENDAHAN, A.B, BRAGA, R.M. Acabamento de Cordeiros em Confinamento. Documento 03, Embrapa Boa Vista- RR 2005.

BerChielli, T. T. PIRES, A. V. OliVeirA, S. G. Nutrição de Ruminantes. Editora Afiliada, Jaboticabal-SP, Funep, 2006, 538 p.

BORGES, A.L.C.C. Controle da ingestão de alimentos. Belo Horizonte: Escola de veterinária da UFMG, n.27, 67-79, 1999. (Caderno técnico).

BORGES, C. H. P, BRESSLAU, S. Manejo e alimentação de cabras em lactação. Treinamento em Gado Leiteiro-PURINA, Belo Horizonte-MG, 2003.

BUENO, M.S, CUNHA, E. A. SANTOS, L. E, et al. Características de Carcaça de Cordeiros Suffolk Abatidos em Diferentes Idades. Revista Brasileira de Zootecnia, 29(6): 1803-1810, 2000.

BUENO, M. S. SANTOS, L. E. CUNHA, E. A. Alimentação de ovinos criados intensivamente. Instituto de Zootecnia. Nova Odessa-SP, 2007.

CALFAT, J. Cordeiro de corte: um mercado inexplorado. Disponível em: www.cordeirobrasileiro.com.br.boletim 5. Acesso: 10/08/2009, 2009.

CARVALHO, S. BROCHIER, M. A. PIVATO, J, et al. Desempenho e avaliação econômica da alimentação de cordeiros confinados com dietas contendo diferentes relações volumoso:concentrado.Revista Ciência Rural Santa Maria, v.37, n. 5, p.1411-1417, setout, 2007.

CLEMENTINO, R.H, SOUSA, W.H, MEDEIROS, A.N. et al. Influência dos níveis de concentrado 
BORELLA, G. et al. Alimentação e grupo genético de ovinos terminados em confinamento: Revisão de literatura. PUBVET, Londrina, V. 5, N. 1, Ed. 148, Art. 995, 2011.

sobre os cortes comerciais, os constituintes não-carcaça e os componentes da perna de cordeiro confinado. Revista Brasileira de Zootecnia, v.36, n.3, p.681-688, 2007.

CUNHA, M.G.G, CARVALHO, F.F.R, NETO, S.G, et al. Características quantitativas de carcaça de ovinos Santa Inês confinados alimentados com rações contendo diferentes níveis de caroço de algodão integral. Revista Brasileira de Zootecnia, v.37, n.6, p.1112-1120, 2008.

CUNHA, M. G. G. CARVALHO, F. F. R. VÉRAS, A. S. C, et al. Desempenho e digestibilidade aparente em ovinos confinados alimentados com dietas contendo níveis crescentes de caroço de algodão integral. Revista Brasileira de Zootecnia, v.37, n.6, p.1103-1111, 2008.

ESTRADA, L.H.C. Exigências nutricionais de ovinos para as condições brasileiras. In: CONGRESSO DA SOCIEDADE NORDESTINA DE PRODUÇÃO ANIMAL, 2., 2000, Teresina. Anais... Teresina: SNPA, 2000. v I. p. 325-339, 2000.

ESTRADA, L.H.C. Exigências Nutricionais de Ovinos para as condições Brasileiras. Universidade Estadual do Norte Fluminense Centro de Ciências e Tecnologias Agropecuárias Laboratório de Zootecnia e Nutrição Animal Núcleo de Pesquisa em Caprinos e Ovinos, 2008.

FORBES, J.M. Voluntary intake and diet selection in farm animals. Wallingford: $C A B$ Publishing, 1995. 544p.

FREITAS, A. W. P. ROCHA, F. C. ZONTA, A, et al. Consumo de nutrientes e desempenho de ovinos alimentados com dieta à base de cana-de-açúcar hidrolizada. Pesq. agropec. bras., Brasília, v.43, n.11, p.1569-1574, nov. 2008.

GERASEEV, L. C. PEREZ, J. R. O. PEDREIRA, B. C. Manejo alimentar de cordeiros - alguns aspectos. Disponível em: www.editora.ufla.br, acesso em: 22/08/2009, ano de acesso, 2009.

JÚNIOR, W. P. RIBEIRO, E. L. A. MIZUBUTI, I. Y, et al. Níveis de energia na alimentação de cordeiros em confinamento e composição regional e tecidual das carcaças. Revista Brasileira de Zootecnia, v.38, n.9, p.1797-1802, 2009.

LEITE, E.R. et al. Sistema de produção de caprinos e ovinos de corte para o Nordeste Brasileiro. Disponível em: www.sistemasdeproducao.cnptia.embrapa.br. Acesso em: 14/09/2009, 2005.

MACEDO, F.A.F. Desempenho e características de carcaças de cordeiros Corriedale e mestiços Bergamácia x Corriedale e Hampshire Down x Corriedale, terminados em pastagem e confinamento. Botucatu, SP: UNESP, 1997. 72p. Tese (Doutorado em Zootecnia) - Universidade Estadual Paulista -Faculdade de Medicina Veterinária e Zootecnia de Botucatu, 1998.

MACEDO, F. A. F. SIQUEIRA, E. R. MARTINS, E. N. Desempenho de cordeiros Corriedale, puros e mestiços, terminados em pastagem e em confinamento. Arquivo Brasileiro de Medicina Veterinária e Zootecnia vol.51 n.6 Belo Horizonte Dec. 1999.

MADRUGA, M. S, SOUSA, W. H, ROSALES, M. D. et al. Qualidade da carne de cordeiros Santa Inês terminados com diferentes dietas. Revista Brasileira de Zootecnia, v. 34, n.1, p. 309315, 2005.

MEDEIROS, L.P, GIRÃO, R. N. et al. CAPRINOS-princípios básicos para sua exploração. Embrapa CPAMN/SPI, 1994, 177 p. 
BORELLA, G. et al. Alimentação e grupo genético de ovinos terminados em confinamento: Revisão de literatura. PUBVET, Londrina, V. 5, N. 1, Ed. 148, Art. 995, 2011.

MEDEIROS, G. R. CARVALHO, F. F. R. FERREIRA, M. A. et al. Efeito dos níveis de concentrado sobre o desempenho de ovinos Morada Nova em confinamento.Revista Brasileira de Zootecnia, v.36, n.4, p.1162-1171, 2007.

MONTEIRO, E. M. SHIMOKOMAKI, M. SILVA, M. D. P, et al. Efeito do genótipo nas características morfológicas e histiquímicas do Longissimus dorsi e em alguns parâmetros quantitativos das carcaças de cordeiros. Ciênc. agrotec., Lavras, v.24 (Edição Especial), p.153-162, dez., 2000.

MONTEIRO, E.M. Biossegurança e Carne Orgânica. II Encontro de CaprinoOvinocultores de corte da Bahia, 2002. p. 89 a 104.

OLIVIERA, M. V. M, PÉREZ, J. R. O, GARCIA, I.F.F et al. Desempenho de Cordeiros das Raças Bergamácia e Santa Inês, Terminados em Confinamento, Recebendo Dejetos de Suínos como Parte da Dieta. Revista Brasileira de Zootecnia, v.32, n.6, p.1391-1396, ano 2003.

OLIVEIRA, F. GALVANI, D. B. PIRES, C. C, et al. Viabilidade econômica da terminação de cordeiros em confinamento para abate entre $25 \mathrm{~kg}$ e $35 \mathrm{~kg}$ de peso vivo. Parte de dissertação de Mestrado, UFSM, 2007.

OLIVEIRA, A.W. Produção de Cordeiros. Disponível em: www.agronline.com.br, ano 2008, acesso em 04/08/2009.

PEREIRA, M. S. RIBEIRO, E. L. A. MIZUBUTI, I. Y, et al. Consumo de nutrientes e desempenho de cordeiros em confinamento alimentados com dietas com polpa cítrica úmida prensada em substituição a silagem de milho. Revista Brasileira de Zootecnia, v.37, n.1, p.134-139, 2008.

PILAR, R.C, PEREZ, J.R.O, SANTOS, C.L, et al. Considerações sobre produção de Cordeiros. Disponível em: www.editora.ufla.br. Acessodo em: 12/08/2009, 2002.

PINHEIRO, R.S.B, JORGE,R.C.M, NETO, A.P. et al. Qualidade da carne decordeiros confinados recebendo diferentes relações de volumoso:concentrado na dieta. Ciência Tecnologia de Alimento vol. $29 \mathrm{n}^{\circ} .2$ Campinas abr./jun. 2009.

PINTO, C. W.C. SOUZA, W. H. FILHO, E.C.P, et al. Desempenho de cordeiros Santa Inês terminados com diferentes fontes de volumosos em confinamento. Agropecuária Técnica, v.26, n.2, 2005.

PIRES, C.C. CARVALHO, S. GRANDI, A, et al. Características Quantitativas e Composição Tecidual da Carcaça de Cordeiros terminados em Confinamento.Revista Ciência Rural Santa Maria, v. 29, n. 3, p. 539-543, 1999.

PIRES, C.C, SILVA, L.S, SCHLICK, F.E, et. al. Cria e Terminação de Cordeiros confinados. Revista Ciência Rural, Santa Maria, v.30, n.5, p.875-880, ano 2000.

RIBEIRO, S.D.A. Caprinocultura: Criação Racional de Caprinos. Editora Nobel, São Paulo$\mathrm{SP}, 1997,318 \mathrm{p}$.

ROCHA, M. H. M. SUSIN, I. PIRES, A. V, et al. Performace of Santa Ines lambs fed diets of variable crude protein levels. Sci. Agric. (Piracicaba, Braz.), v.61, n.2, p.141-145, Mar./Apr. 2004.

SANTOS, C.L. Desenvolvimento do Tecido Adiposo em Carcaças de Ovinos e Caprinos. III Encontro de Caprino-Ovinocultores de Corte da Bahia, Anais, 2003. 
BORELLA, G. et al. Alimentação e grupo genético de ovinos terminados em confinamento: Revisão de literatura. PUBVET, Londrina, V. 5, N. 1, Ed. 148, Art. 995, 2011.

SANTOS, R. A criação da cabra e da ovelha no Brasil. Editora Agropecuária Tropical, Uberaba-MG, ano 2004, 496 p.

SANTOS, E.M. Estimativa de consumo e exigências nutricionais de proteína e energia de ovinos em pastejo no semi-árido. Patos-MG, Universidade Federal de Campina GrandeCentro de Saúde e Tecnologia Rural. Campus de Patos programa de Pós-Graduação em Zootecnia Sistema Agrossilvipastoris, 42 p., 2006.

SANTOS, J.W, CABRAL, L.S, ZERVOUDAKIS, J.T, et. al. Níveis de grão de capim- pé-de-galinha (Eleusine coracana) em dietas para ovinos: consumo e digestibilidade. Revista Brasileira de Zootecnia, v.37, n.10, p.1884-1889, ano 2008.

SANTOS, J. W. CABRAL, L. S. ZERVOUDAKIS, J. T, et al. Casca de soja em dietas para ovinos. Revista Brasileira de Zootecnia, v.37, n.11, p.2049-2055, 2008.

SILVA, S. C.; PEDREIRA, C.G.S. Fatores condicionantes e predisponentes da produção animal a pasto. XIII SIMPÓSIO SOBRE MANEJO DA PASTAGEM. 1996. Produção de bovinos a pasto. Anais... (ed.). - Piracicaba: FEALQ, 1997.

SILVA, L.F, PIRES, C. L. Avaliações Quantitativas e Predição das Proporções de Osso, Músculo e Gordura da Carcaça em Ovinos. Revista Brasileira de Zootecnia, 29(4): 1 253-1260, 2000.

SIMPLICIO, A.A, BARROS, N.N, ALVES, J.U. Exploração intensiva de Caprinos e Ovinos para carne e pele. VI Seminário Nordestino-PECNORDESTE, III Semana da CaprinoOvinocultura Brasileira, 2002.

SIQUEIRA, E.R, SIMÕES, C.D, FERNANDES, S. Efeito do Sexo e do Peso ao Abate sobre a Produção de Carne de Cordeiro. Morfometria da Carcaça, Pesos dos Cortes, Composição Tecidual e Componentes não constituintes da carcaça. Revista Brasileira de Zootecnia,v.30 $\mathrm{n}^{\circ} .4$ Viçosa . 2001.

SIQUEIRA, E.R. Criação de ovinos de corte. Universidade On-line de Viçosa-MG, ano 2008, $524 \mathrm{p}$.

SOBRINHO, A.G.S, PURCHAS, R.W, KADIM, I.T, et al. Características de Qualidade da Carne de Ovinos de Diferentes Genótipos e Idades ao Abate. Revista Brasileira de Zootecnia, v.34, n.3, p.1070-1078, 2005.

SOBRINHO, A. G.S, MACHADO, M. R. F. GASTALDI, K. A, et al. Efeitos da Relação Volumoso: Concentrado e do Peso ao Abate sobre os Componentes da Perna de Cordeiros Ile de France $x$ Ideal Confinados. Revista Brasileira de Zootecnia, v.31, n.2, p.1017-1023, 2002.

TURINO, V. F. SUSIN, I. PIRES, A. V, et al. Casca de soja na alimentação de cordeiros confinados: desempenho e características de carcaça. Revista Ciência Animal Brasileira, v. 8, n. 3, p. 495-503, jul./set. 2007.

VALVERDE, C.C. Hábitos alimentares dos Ovinos, 250 Maneiras de Preparar Rações Balanceadas. Editora Aprende Fácil, 2005.

VAN SOEST, P.J. Nutricional ecology of the ruminant. 2ed. New York: Cornell University Press, 1994. 476p. 
BORELLA, G. et al. Alimentação e grupo genético de ovinos terminados em confinamento: Revisão de literatura. PUBVET, Londrina, V. 5, N. 1, Ed. 148, Art. 995, 2011.

ZUNDT, M, MACEDO, F.A.F, MARTINS, E.N, et al. Desempenho de Cordeiros Alimentados com Diferentes Níveis Protéicos. Revista Brasileira de Zootecnia, v.31, n.3, p.1307-1314, 2002.

YAMAMOTO, S. M MACEDO, F. A. F. ZUNDT, M, et al. Fonte de óleo vegetal na dieta de cordeiros em confinamento. Revista Brasileira de Zootecnia, v.34, n.2, p.703-710, 2005. 